\title{
Design of College Teacher Workload Management System Based on ASP.NET
}

\author{
Dongsheng Zhou , Bo Hu \\ Information \& Electric Engineering College \\ Shenyang Agricultural University \\ Shenyang, 110866, China \\ Zhoudsh8021@sina.com, Boer5109@sohu.com
}

\begin{abstract}
This paper mainly introduces a management information system about college teacher workload based on ASP.NET and ADO.NET technology. The system adopts B/S structure, benefits the using of client. And the system realized the digital and dynamical management, reduces the time of examination and approval, improves the efficiency and veracity of work. The paper analyses the theory of system development, function of system, and design scheme of system.
\end{abstract}

Keywords-component;ASP.NET; teacher workload; MIS; B/S framework;

\section{INTRODUCTION}

With the development of information technology, more and more management information system was developed in the university and college, for example, personnel management system, office automation system, but the function do not include the teacher workload management.

It is a important and trivial work that the entry and summary of teacher workload in the university and college. With the amount of teacher and the increase of teaching task, the tranditional work model has not solved efficiently the problem. Tranditional manual management exits the following disadvantage:

- Calculation workload wastes more time of educational administration personnel.

- Manual calculation and formula proned the errors, but the correction of workload calculation relationship with the personal profit of every teacher.

- More time, lower efficiency.

- It is disadvantage of that the summary, statistics and quety of teacher workload.

So it is inevitable that importing the management information system, through the system, established the platform to realize the information and automation. The paper put forword the method of teacher workload based on ASP.NET, and analyses the theory of system development, function of system, and design scheme of system.

\section{TEACHING WORK INDEX QUANTIFICATION}

\section{A. Classroom Teaching Workload Index Qyantification}

In order to calculate convenient the teaching workload, we must establish the standard index quantification, including classroom teaching, experimental teaching, graduation design, prduction practice, publishing papers, etc. For example, the equation of Calculating classroom teaching standard school as follows:

Standard_school=(plan_school+2)*Sum_coefficient

Standard_school - teachin standard school;

plan_school-teaching plan school;

Sum_coefficent includes several coefficient.

- Number of teaching coefficient, based on 30 persons as standard, add 0.007 exceed a person.

- Course category coefficient, -0.1 as physical education, other as 0 .

- Course level coefficient, PhD. Programs add 0.2, master course adds 0.1 .

- Teaching method coefficient, bilingual teaching adds 0.3 , and the school encouraged the teaching method.

- Other coefficient. It refers to the new course or the new staff , and the test course of teaching reform.

\section{B. The Total of Teaching Workload}

The workload includes other work, for example, invigilation, teaching research, published textbooks, guiding all kinds of activities, guiding graduate students. The total of teaching workload is the sum of what is mentioned above.

\section{SYSTEM ANALYSIS AND DESIGN}

\section{A. System Structure Design}

Based on the survey and detailed requirement analysis, the system includes five modules: teacher information management module, teaching work management module, subsidiary work management module, query module and system configure module. The structure as shown in figure 1.

\section{B. Database design}

The system adopts SQL Server 2008 as the DBMS. And the programming adopts ASP.NET. The database is the important part of the system, is the basis of the whole system. The followings are the structure of several important tables.

- Teacher. It stores teacher basic information. 


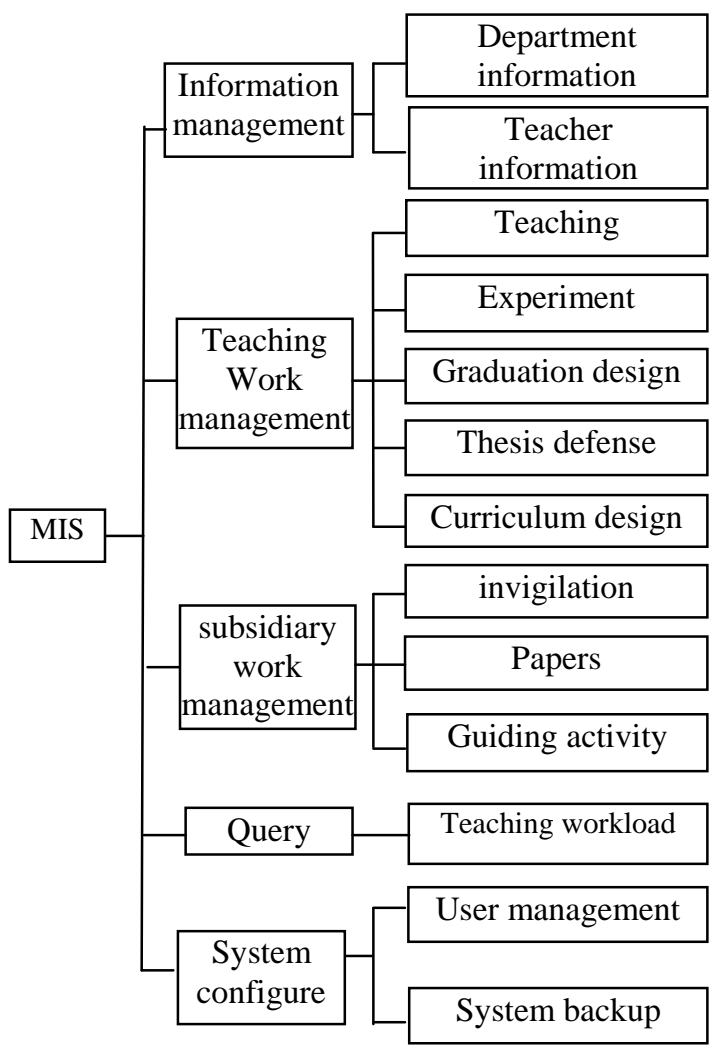

Figure 1. System structure.

TABLE I. TABLE OF TEACHER

\begin{tabular}{cc}
\hline Name of field & Description of field \\
\hline T_number & Teacher number \\
T_name & Teacher name \\
T_head & Head of teaching \& research section \\
T_Dean & Teaching dean \\
\hline
\end{tabular}

- Course. It stores courses information, including theory school, experiment school, course name, course code,etc. Table 1 is the stucture of course table.

TABLE II. TABLE OF COURSE

\begin{tabular}{cc}
\hline Name of field & Description of field \\
\hline C_code & Course code \\
C_name & Course name \\
C_Tschool & Theory school \\
C_Eschool & Experiment school \\
\hline
\end{tabular}

- Teaching information. It stores every teaching information.

TABLE III. TABLE OF TEACHING INFORMATION

\begin{tabular}{cc}
\hline Name of field & Description of field \\
\hline C_code & Course code \\
C_number & Course serial number \\
T_number & Teacher number \\
S_number & Sutdents number \\
\hline
\end{tabular}

\section{KEY TECHNOLOGY}

\section{A. Choice of Key Technology}

The system adopts ASP.NET, backend database is SQL

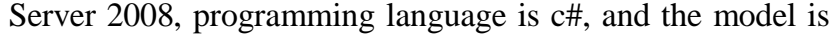
$\mathrm{B} / \mathrm{S}$, the users is more convenient, needn't setup other software s but a web browser.

\begin{tabular}{|c|c|c|c|c|}
\hline VB.NET & $\mathrm{C}++$ & $\mathrm{C \#}$ & $\mathrm{J} \#$ & Other language \\
\hline & mmon & ngua & e spe & ification \\
\hline ASP & & & & Windows forms \\
\hline & & NET & $\& X$ & \\
\hline & & e clas & libra & \\
\hline & Comm & lang & age 1 & untime \\
\hline Winc & & & & Com+ \\
\hline
\end{tabular}

Figure 2. .NET Platform System structure.

$\mathrm{B} / \mathrm{S}$ system structure runs in the browser of the client, more business logic realizes in the serve, update and maintenance the software in the server, it reduces the workload and the cost of work. It realizes that different person visit database, operate database on the different position, in the different time. Managers can Manage efficiently the database, control the authority of the platform and the database.

ASP.NET script technology based on the, .NET framework module. $\mathrm{C \#}$ as the development language, combined the character of $\mathrm{C} / \mathrm{C}++$ and Visual Basic, the function more great, the operation more simple.

SQL Server 2008 affords the platform of the data management and analysis platform. Through ADO.NET data access structure, visits safely the database.

\section{B. Application of Key Technology}

- Code-behind technology

ASP.NET adopts code-behind technology to realize the separation of static webpage and programming code. In the tranditional web page, the both was combined the same page, if the static webpage occured change, then the code must change synchronously, made trouble for the programming developer, now the new technology solved the above problem and make the both part separate.

ASP.NET adopts the way of page inheritance. Front desk .aspx file can separated from behind desk .cs file, make the structure more clearly and after compiled the code is more concealed, so improve the security of the program and the website.

- Application of server control

Server controls are the most important part that establish ASP.NET application programming, they are the 
components that were run in the server, afford the interaction function of client and server.

Through application of server control, we can solve the problem. It includes Html server control, it can run the advanced function in the server, the web control has not the function. Addition, the application also adapts the validation control, it reduces the load of the server, make some functions run in the client, realize double validation, confirm the security of the application.

- Application of stored procedure

Stored procedure is a group of specific function SQL statement, is a program through Transact-SQL, it strongthens the function and flexibility of SQL language, and can complete complex judgement and operation, protect the security and integrity of data, postoptimality the plan, improve the property of SQL, and the stored procedure can repeated use , improve the system run efficiency.

- Application of crystal reports

Crystal reports was used to design the report. It integrates the most of tools for software development, especially with .NET platform, save the time and make the customers satisfaction, it has two modul: Pull modul and Push modul.

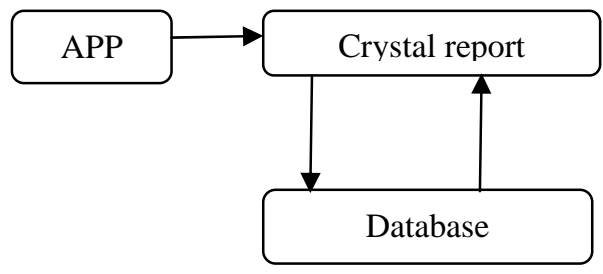

Figure 3. Pull modul.

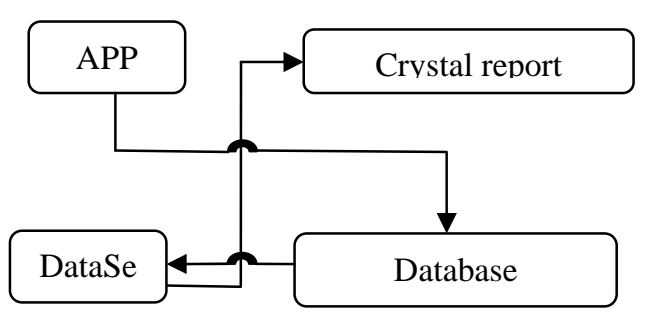

Figure 4. Push modul.

- $\quad$ Event driven programming modul

ASP.NET adapts the event driven programming modul. The modul is a most important character that adapts ObjectOriented Programming. It can be developed like developed form program, make the work become simple.

\section{CONCLUSION}

The paper based on the demand of the teaching workload in the college and university, through the analysis detailed, considered the user demand and teaching practice, design the structure modul and database structure, choose the typical case as the sample , state the application of key technology in the system. The system solved the problem that teaching workload in the university, liberated the educational administration manager, avoided the plenty of calculation, and improve the accuracy of calculation, promoted the paperless office to a more higher platform. Of course, the system has some of deficiencies, I hope that experts will make more valuable advice.

\section{ACKNOWLEDGMENT}

The development of the system was relationship with the school educational administration department, they paid a lot of time and energy. Here, I told my heartfelt to them.

\section{REFERENCES}

[1] John Kauffman, Bradley Millington, "Beginning ASP.NET 2.0 and Database,” Tsinghua University Press, Beijing(2007), .

[2] Bill Evjen, Scott Hanselman, Devin Rader, "Professional ASP.NET 3.5 SP1 in C\# and VB,” Tsinghua University Press,Beijing(2010)..

[3] Y.L Cao “ASP/ASP.NET Database Development Practical Engineering Projects Selected,” Posts \& Telecom Press, Beijing(2005).

[4] Y.T Zhang, Hongbing Ding, “ASP.NET Network Programming Standard Tutorial,” Posts \& Telecom Press, Beijing(2005).

[5] Z.C Chen,Y.J Ma, Z.L Zhang, “ASP.NET Network Programming Ttechnology \& Practice,”, Tsinhua University Press, Beijing(2008).

[6] P Zhang, "ASP.NET General modul and Typical Example Development Navigation ,” Posts \& Telecom Press, Beijing(2009).

[7] Y.B Zhang, X.H Tan, K Xiao, “The Design \& Application of Teachin Workload Management System Based on Web,” China Management Informationization, China, vol. 15, 69-71, January 2012.

[8] L.G, F.L, B Xue, "The Implement of College Teacher Workload Management System Based on ASP.NET,” Journal of Zhongyuan University of Technology, vol. 18, 55-59, 2007.

[9] H.A Wei, Y.W Xu , "The Design and Implement of Workload Management System Based on ASP.NET,” Digital Technonlogy and Application, 175-176, 2012.

[10] P Zhang, “ASP.NET General modul and Typical Example Development Navigation ,” Posts \& Telecom Press, Beijing(2009).

[11] Zh.Y Sun, Y Zhang, “ The Design and Implement of Online Teacher Evaluation System Based on B/S Modul, ” Computer Applications and Software, 183-186, March 2012. 